\title{
Production of Liquid Hydrocarbons from Pretreated Bio-oil via Catalytic Deoxygenation with Syngas
}

\author{
Sathish K. Tanneru and Philip H. Steele* \\ Department of Sustainable Bioproducts, Mississippi State University, Mississippi State, \\ Starkville, MS \\ *Corresponding author: psteele@cfr.msstate.edu
}

\begin{abstract}
:
Biomass-derived fast pyrolysis oil (bio-oil) is a potential alternative replacement for conventional transportation fuels. But negative properties such as lower energy density, higher water content and acidity prevent the direct use of pyrolysis oil as a fuel. Catalytic deoxygenation of pyrolysis oils to hydrocarbons has been studied widely with application of high heat and hydrogen pressure. However, consumption of a large amount of expensive hydrogen has remained a problem for this technology. Therefore, development of an efficient and reduced hydrogen deoxygenation method would be desirable. In this study, we have applied catalytic deoxygenation of pretreated bio-oil in the presence of pressurized syngas to produce liquid hydrocarbons. The pretreatment is an oxidation step that converts aldehydes to carboxylic acids that are more conducive to catalytic conversion to hydrocarbons than are raw bio-oils. The pretreated bio-oil allowed performance of a partial deoxygenation step with a low amount of hydrogen (syngas). This partially deoxygenated product was then fully deoxygenated with pure hydrogen to produce hydrocarbons. Properties of the resultant liquid hydrocarbons were analyzed by ASTM standards for transportation fuels. The hydrocarbon mixture obtained by our process was analyzed by Fourier transform infrared spectroscopy, detailed hydrocarbon analysis, nuclear magnetic resonance spectroscopy and simulated distillation.
\end{abstract}

Keywords: Pyrolysis oil, oxidation, pretreatment, catalytic deoxygenation, liquid hydrocarbons.

\section{Introduction:}

Fast pyrolysis is one thermochemical process for conversion of biomass to liquid products. Bio-oil produced from fast pyrolysis of biomass is a potential alternative fuel to replace conventional fuels. Fast pyrolysis includes heating the biomass at rapidly elevated temperatures in the range of 400 to $550{ }^{\circ} \mathrm{C}$ in the absence of oxygen. More specifically, bio-oil is a dark brown liquid with pungent phenolic odor. Bio-oil chemical properties vary with material utilized for its production or the conditions under which it is produced [1-4]. Bio-oil has environmental advantages when compared to conventional fuels, because when combusted, bio-oil produces less pollution than fossil fuels, it produces half the $\mathrm{NO}_{\mathrm{x}}$, negligible quantities of $\mathrm{SO}_{\mathrm{x}}$ emissions and it is considered $\mathrm{CO}_{2}$ neutral [5-6]. However, there are serious disadvantages when using raw bio-oils for other than heating fuels. For example, untreated bio-oil has a high water content, high acidity, immiscibility with petroleum products, its viscosity increases over time and when heated, and it has a distinctive odor.

Chemically, bio-oil is a complex mixture of water (15-30\%), carboxylic acids (10-25\%), aldehydes (10-15\%), ketones (1-5\%), alcohols (2-5\%), sugars (5-15\%), phenols $(5-10 \%)$, furans and pyrans $(1-5 \%)$ and $10 \%$ miscellaneous compounds $[2,3,6-8]$. When tested for use as an 
engine fuel, bio-oil has caused damage to all but Sterling engines. In light of the many disadvantages of using untreated bio-oil as a fuel, it has not been adopted for commercial use except as a heating fuel in some limited applications $[9,10]$.

Advanced fuels are liquid transportation range fuels such as green gasoline, jet fuel and green diesel fuels that are derived from renewable sources. They are defined as fuels that can reduce greenhouse gas emissions by 50 percent compared to fossil fuels [11]. The Renewable Fuel Standard II (RFS2) mandates the increased production of advanced fuels to 5.5 billion gallons by 2015 [12]. Therefore, considerable research has been focused on the production of advanced fuels from renewable resources by various upgrading technologies.

Current bio-oil upgrading techniques to produce transportation fuels include deoxygenation $[13,14]$, catalytic pyrolysis $[15,16]$ and steam reforming [17] mainly to reduce the oxygen content present in the bio-oil. Deoxygenation is a method by which oxygen is removed from oxygenated compounds. Deoxygenation can be applied by hydrodeoxygenation (HDO) or decarboxylation [18-24]. The general HDO reaction is shown as Scheme $1[19,25]$.

$$
-(\mathrm{CHO})-+\mathrm{H}_{2} \stackrel{\text { Catalyst }}{\longrightarrow}-(\mathrm{CH})-\quad+\mathrm{H}_{2} \mathrm{O} \quad \text { Scheme } 1 .
$$

HDO of bio-oil with pure pressurized hydrogen in the presence of suitable catalysts has been demonstrated to reduce the oxygen content of bio-oil and produces a liquid hydrocarbon mixture that can be utilized as a transportation fuel. In general, HDO can be performed in one, two, or more steps. It has become traditional to hydroprocess fast pyrolysis oil by an initial $1^{\text {st }}$ stage hydrotreating step at mild temperatures $\left(200-400{ }^{\circ} \mathrm{C}\right)$ to prevent bio-oil polymerization; typical hydrogen pressure applied for this $1^{\text {st }}$ stage ranges from 4 to $10 \mathrm{MPa}$ in the presence of a heterogeneous hydrotreating catalyst. In the $2^{\text {nd }}$ stage, a hydrocracking step is performed at more severe temperatures $\left(300-500{ }^{\circ} \mathrm{C}\right)$ and also at high pressure ranges from 10 to $20 \mathrm{MPa}$ in the presence of a heterogeneous hydrocracking catalyst [6,13-14,18-22,24-28]. However, conversion of bio-oil to hydrocarbons via application of pure hydrogen requires a large volume of expensive hydrogen to deoxygenate the bio-oil.

Bio-oil aldehydes play a vital role in bio-oil stability from thermal application or continued stability over time. Aldehydes readily react with phenols and sugars to form higher molecular weight resins and oligomers via polymerization and condensation; oligomerization reactions lead to coke formation [21,29,30]. Aldehydes present in the raw bio-oil can be converted to carboxylic acids by subjecting them to oxidation [31-34].

Steele et al. [32], Parapati et al. [33] and Tanneru and Steele [34] demonstrated that pretreatment of raw bio-oil by oxidation increased the acid value of oxidized bio-oil from 90.392.5 to $161.0-165.7 \mathrm{mg} \mathrm{KOH} / \mathrm{g}$. Further, Tanneru and Steele [34] showed that this high-acid value bio-oil allowed performance of the hydrotreating step, utilizing pure hydrogen, with low hydrogen pressure and reduced hydrogen consumption. Properties of the hydrotreated oxidized bio-oil were also improved with a $30 \%$ higher organic fraction yield and reduction of char and water content by approximately $92 \%$ and $46 \%$, respectively.

There has been increased interest by researchers in recent years to produce hydrogen by various technologies to allow hydrogen to be utilized as a versatile fuel. Much interest is in its use as a transportation fuel. This is due to the fact that hydrogen combustion produces only water as a byproduct. Hydrogen can be produced from the water gas shift (WGS) reaction shown in Scheme $2[35,36]$. Synthesis gas produced purposely by biomass gasification contains significant percentages of both hydrogen and $\mathrm{CO}$ in addition to other gases with nitrogen and $\mathrm{CO}_{2}$ being the 
major additional gases. Despite the presence of other gases the WGS reaction will occur when the syngas is pressurized, the proper heat is applied and in the presence of an effective WGS catalyst and water [35,37,38]. Bio-oil water content typically ranges from 25 to $30 \mathrm{wt} \%$. Therefore, the theoretical conditions $\left(\mathrm{CO}\right.$ and $\left.\mathrm{H}_{2} \mathrm{O}\right)$ are present for utilization of the WGS reaction to produce increased hydrogen content in biomass syngas during bio-oil catalysis.

$$
\mathrm{CO}+\mathrm{H}_{2} \mathrm{O} \stackrel{\text { Catalyst }}{\longleftrightarrow} \mathrm{H}_{2}+\mathrm{CO}_{2} \quad \text { Scheme } 2 .
$$

The objective of this research was to extend the work of Tanneru and Steele [34] to conserve hydrogen by utilization of syngas which contains a low percentage of hydrogen. We hypothesized that the WGS reaction will take place by reaction of the $\mathrm{CO}$ contained in the syngas with the water contained in the oxidized bio-oil during partial deoxygenation. This was hypothesized to produce sufficient additional hydrogen to allow the partial deoxygenation reaction to occur during the $1^{\text {st }}$ stage of partial deoxygenation. The $2^{\text {nd }}$ stage of full deoxygenation of the partially deoxygenated product was performed in the presence of pressurized pure hydrogen. We will term this combination of $1^{\text {st }}$-stage syngas partial deoxygenation followed by $2^{\text {nd }}$-stage full hydrogen deoxygenation as catalytic deoxygenation $(\mathrm{CDO})$ in this paper.

\section{Materials and methods}

\subsection{Chemicals and materials}

Bio-oil required for this research was produced from loblolly pine wood chips with a particle size of 1-3 mm and moisture content of $8-10 \%$ on a dry weight basis. Bio-oil was produced by fast pyrolysis performed at a temperature of $450{ }^{\circ} \mathrm{C}$ with nitrogen carrier gas at a rate of $7-\mathrm{kg} / \mathrm{h}$ with an auger-feed pyrolysis reactor located in the Department of Sustainable Bioproducts, Mississippi State University (MSU). The MSU auger fast pyrolyzer produced $60-65 \mathrm{wt} \%$ of liquid product, $10-15 \%$ of non-condensable gases and $20-25 \%$ of char on a dry biomass weight basis.

Biosyngas utilized in this study was produced in a downdraft gasifier at Mississippi State University and compressed to 1500 psi in laboratory tanks for our experiments. Production of synthesis gas was performed with a Bio Max 25 gasifier. This syngas was comprised of approximately $18-20 \%$ hydrogen, $19-22 \%$ carbon monoxide, $11 \%$ carbon dioxide, $2 \%$ methane and $47-49 \%$ nitrogen $[35,39]$. Hydrogen gas used in this research was obtained from nexAir.

Potassium carbonate, hydrogen peroxide $\left(\mathrm{H}_{2} \mathrm{O}_{2}\right) 50 \mathrm{wt} \%$ solution in water, chloroform-d $\left(\mathrm{CDCl}_{3}\right) 99.96$ atom \% D contains $0.03 \%$ (v/v) TMS, oxone (potassium monopersulfate triple salt) and copper(II)oxide were obtained from Sigma-Aldrich. Nickel on silica-alumina $(66 \pm 5 \%$ $\mathrm{Ni}$ ) catalyst powder was obtained from Alfa Aesar. All chemicals were used with no further purification.

\subsection{Methods}

\subsubsection{Pretreatment of raw bio-oil by oxidation}

Oxidation pretreatment was performed in a stainless steel, high-pressure batch autoclave reactor equipped with an overhead magnetic stirrer, a pressure indicator with a maximum capacity of $5000 \mathrm{psig}$ and a thermocouple for temperature monitoring in the range of $0-500{ }^{\circ} \mathrm{C}$. The autoclave was equipped with an electrical heating and cooling system to control the reactor 
temperature. Oxidation pretreatment was applied to raw bio-oil by addition of a mixture of oxone $/ \mathrm{H}_{2} \mathrm{O}_{2}$ (oxidizing agent) followed by stirring for $90 \mathrm{~min}$ at room temperature and without applied pressure. This oxone $/ \mathrm{H}_{2} \mathrm{O}_{2}$ solution was prepared by dissolving $5 \mathrm{wt} \%$ of oxone in 10 wt $\%$ of commercial $50 \mathrm{wt} \% \mathrm{H}_{2} \mathrm{O}_{2}$ solution. No additional water was added to prepare oxone $/ \mathrm{H}_{2} \mathrm{O}_{2}$. This oxidation pretreatment significantly increased the bio-oil acid value by converting aldehydes into carboxylic acids. This pretreated bio-oil (oxidized product) was utilized as a precursor material to produce hydrocarbons by CDO.

\subsubsection{Catalytic deoxygenation of pretreated bio-oil}

CDO comprised of partial deoxygenation followed by full deoxygenation was performed in the same Parr batch autoclave described above. The $1^{\text {st }}$-stage partial deoxygenation of the oxidized product was performed in the presence of a mixture of nickel on silica-alumina (5 wt $\%)$, potassium carbonate $(3 \mathrm{wt} \%)$ and copper(II)oxide $(2 \mathrm{wt} \%)$ catalyst at a temperature of $360{ }^{\circ} \mathrm{C}$ and under pressurized syngas at $5.5 \mathrm{MPa}$ for about $90 \mathrm{~min}$. The optimized reaction time was selected by performing the experiments from 30-120 min at a time interval of $30 \mathrm{~min}$. Based on high HHV, lower AV and higher organic fraction the best reaction time 90 min was selected. At the 90 min reaction temperature was tested from $280-400{ }^{\circ} \mathrm{C}$ for every interval of $40{ }^{\circ} \mathrm{C}$. In the $2^{\text {nd }}$-stage, the partially deoxygenated top oil fraction was separated and fully deoxygenated by a mixture of nickel on silica-alumina $(5 \mathrm{wt} \%)$ and copper(II)oxide $(2 \mathrm{wt} \%)$ catalyst at a temperature of $425{ }^{\circ} \mathrm{C}$ and under pressurized hydrogen at $9.6 \mathrm{MPa}$ for about $150 \mathrm{~min}$. As a control, partial deoxygenation of direct raw bio-oil with syngas was also performed at the same $1^{\text {st }}$-stage partial deoxygenation reaction conditions. However, no product was able to be produced due to heavy coke formation during the reaction. Experiments to use raw bio-oil are performed at various (4-6 MPa) syngas pressures. More than $80 \%$ by weight of coke was produced during these attempts. This heavy coke production blocked the reactor. It appears that partial deoxygenation of raw bio-oil with pressurized syngas is not possible unless applied to oxidized bio-oil.

Here, catalysts were selected based on their catalytic activity and previous studies results. As reported by Steele et al. [32] and Parapati et al. [33], Ni on silica-alumina was performed best to promote the hydrodeoxygenation of the bio-oil. Idakiev et al. [40] utilized $\mathrm{CuO}$ to promote the WGS in combination with heterogeneous catalysts. In the present work, various combinations of copper(II)oxide and potassium carbonate were applied to improve the in-situ WGS reaction from water and $\mathrm{CO}$ during the $1^{\text {st }}$ stage of partial deoxygenation reaction. The various percentage combination of these catalysts were tested to select the best catalyst-combination based high $\mathrm{HHV}$, lower AV and higher organic fraction yields. In the second stage interestingly we have observed the combination of Ni-based catalyst and $\mathrm{CuO}$ produced higher yield organic fraction yield.

In each experiment, once the reaction was complete, the liquid products were cooled in the reactor. The mixture was collected in centrifuge test tubes and centrifuged for $2-4 \mathrm{~h}$ to separate the resulting aqueous and organic phases. Both phases were separated and weighed for mass balance computation. The byproducts produced in this process included water and off-gas. Yields were calculated by Eq. 1 [41].

Yield $(\mathrm{wt} \%)$ of organic fraction $=(\mathrm{P}(\mathrm{g}) \times 100) /$ bio-oil weight $(\mathrm{g})$

Eq. 1

Where: $\mathrm{P}=$ products obtained 


\section{Data analysis}

The raw bio-oil, oxidized product, partially deoxygenated product (boiler fuel) and fully deoxygenated product (hydrocarbon mixture) produced were characterized following ASTM methods. Higher heating values (HHV) were determined by Ika-5000 bomb calorimeter by applying the ASTM D240 method. Acid values were determined by dissolving $1 \mathrm{~g}$ of bio-oil in $50 \mathrm{ml}$ of 35:65 ratio of isopropanol to water mixture and titrating to a $\mathrm{pH}$ of 8.5 with $0.1 \mathrm{~N} \mathrm{KOH}$ solution following the method of ASTM D664. $\mathrm{pH}$ values were determined by ASTM E70. Densities were determined by Anton Parr DMA 35n portable density meter by ASTM D4052. Viscosities were determined by Ubbelohde capillary viscometer at $40{ }^{\circ} \mathrm{C}$ water bath temperature according to the ASTM D445. Elemental carbon, hydrogen, and nitrogen were determined by EAI CE-440 elemental analyzer with oxygen content determined by difference according to ASTM D5291. Water content was determined by Karl-Fisher titration by ASTM E203. Fourier Transform Infrared Spectroscopy (FTIR) spectra were obtained by a Varian 3500 FTIR analyzer with standard potassium bromide disk technique and spectra were analyzed by VarianResolutions software. A Varian CP-4900 Micro GC analyzed the gas composition of the remaining gas stream after each batch experiment. A mass balance for the fuels from the best performing catalyst was calculated. Simulated distillation data analysis was performed by ASTM D2887 with gas chromatography. A detailed hydrocarbon analysis (DHA) was performed by ASTM D6730-01. Nuclear magnetic resonance spectroscopy (NMR) spectra were collected using a Bruker $600 \mathrm{MHz}$ spectrometer. Each sample was dissolved in chloroform-d $\left(\mathrm{CDCl}_{3}\right.$ as a solvent) and the proton $\left({ }^{1} \mathrm{H}\right)$ NMR spectra were obtained. The spectra of the oxidized product, the syngas partial deoxygenated product, the liquid hydrocarbon mixture produced by our CDO process and a hydrocarbon mixture comprised of equal parts of commercial petroleum gasoline, jet fuel and diesel were obtained.

\section{Results and Discussion}

Table 1 compares some raw bio-oil and oxidized product physical and chemical properties. As shown in Table 1 raw bio-oil acid value increased from 90.28 to $161.0 \mathrm{mg} \mathrm{KOH} / \mathrm{g}$ following oxidation; viscosity decreased by $45.16 \%$ and water content increased by about $11 \%$. The HHV of the oxidized product decreased from raw bio-oil's 16.01 to $15.40 \mathrm{MJ} / \mathrm{kg}$ probably due to water content increase in oxidized product. Density decreased from 1.22 to $1.14 \mathrm{~g} / \mathrm{ml}$ and $\mathrm{pH}$ was reduced to 2.87 from 3.16. Oxygen content of the bio-oil following oxidation increased somewhat from 53.58 to 58.96. This likely resulted from both increased acid and water content.

Table 1. Comparison of raw bio-oil and oxidized product physical and chemical properties.

\begin{tabular}{|c|c|c|}
\hline Properties & Raw bio-oil & Oxidized product \\
\hline Density, g/mL & 1.22 & 1.14 \\
\hline HHV, MJ/kg & 16.01 & 15.40 \\
\hline Oxygen, wt\% & 53.58 & 58.96 \\
\hline $\begin{array}{c}\text { Total acid value, } \\
\mathrm{mg} \mathrm{KOH} / \mathrm{g}\end{array}$ & 90.28 & 161.0 \\
\hline $\mathrm{pH}$ & 3.16 & 2.87 \\
\hline
\end{tabular}




\begin{tabular}{|c|c|c|}
\hline Water content, vol\% & 30.45 & 33.75 \\
\hline $\begin{array}{c}\text { Kinematic viscosity, } \\
40^{\circ} \mathrm{C}, \mathrm{cSt}\end{array}$ & 12.09 & 6.63 \\
\hline
\end{tabular}

The $1^{\text {st }}$-stage partial deoxygenation of the oxidized product was performed in the presence of a mixture of nickel on silica-alumina ( $5 \mathrm{wt} \%$ ), potassium carbonate (3 $\mathrm{wt} \%$ ) and copper(II)oxide ( $2 \mathrm{wt} \%$ ) catalyst at a temperature of $360{ }^{\circ} \mathrm{C}$ and under pressurized syngas at $5.5 \mathrm{MPa}$ for about $90 \mathrm{~min}$ as described in section 2.2.2. After cooling, the partially deoxygenated product had an aqueous phase at the bottom of the vessel and an oil phase at the top. The aqueous fraction was separated from the oil fraction. A portion of the organic fraction was maintained for testing as a boiler fuel product. The remainder of the organic fraction was subjected to full deoxygenation under hydrogen pressure at $9.6 \mathrm{MPa}$ at a temperature $425{ }^{\circ} \mathrm{C}$ for $150 \mathrm{~min}$ as described in section 2.2.2. The resulting liquid contained both hydrocarbons as a top layer and a small percentage of an aqueous phase at the bottom.

The properties of the oxidized product, the resultant boiler fuel following partial deoxygenation and the hydrocarbon mixture produced by full deoxygenation are given in Table 2. The HHV of the boiler fuel at $35.40 \mathrm{MJ} / \mathrm{kg}$ was more than double the $15.40 \mathrm{MJ} / \mathrm{kg}$ value of the oxidized product. Boiler fuel oxygen content was dramatically reduced from 58.96 to 14.0. Acid value was reduced from 161.0 to 51.6. $\mathrm{pH}$ was increased from 2.87 to 4.24 . Water content of the boiler fuels was only 2.7 vol\% compared to that of the oxidized product at $33.75 \mathrm{vol} \%$. Density was reduced to 1.04 for boiler fuel compared to 1.14 for the oxidized product. Viscosity increased greatly from 6.63 to $28.25 \mathrm{cSt}$.

As a control, partial deoxygenation of raw bio-oil was also performed several times at the same $1^{\text {st }}$-stage partial deoxygenation reaction conditions but the reaction was hindered due to coke formation. The partial deoxygenation of raw bio-oil was not able to be performed with pressurized syngas. It appears that the bio-oil oxidation step is required to produce a product that can be partially deoxygenated with syngas.

The properties of the hydrocarbon mixture were greatly improved above those of the boiler fuel. HHV of hydrocarbon mixture was increased to 45.30 from the boiler fuel HHV of 35.40 $\mathrm{MJ} / \mathrm{kg}$, an increase by $27.97 \%$. Oxygen content was reduced from $14 \mathrm{wt} \%$ to zero and acid value was also decreased to zero from $51.6 \mathrm{mg} \mathrm{KOH} / \mathrm{g}$. $\mathrm{pH}$ was on the basic side at 9.5 . Water content was decreased from 2.7 vol\% to 0.08 vol\%, a decrease by $97.0 \%$. Density was considerably lowered from 1.04 to $0.88 \mathrm{~g} / \mathrm{ml}$; viscosity was reduced significantly from $28.25 \mathrm{cSt}$ to $2.38 \mathrm{cSt}$, a decrease of $91.57 \%$.

Approximately 5.23 MPa of syngas-hydrogen was consumed per liter of bio-oil to perform partial deoxygenation of bio-oil using syngas. But, as a base reaction for partial deoxygenation utilizing pure hydrogen consumed was approximately 15.36 MPa of molecular hydrogen per liter of bio-oil. The consumption of molecular hydrogen was reduced by approximately $66 \%$ by utilization of syngas-hydrogen. The $2^{\text {nd }}$-stage full deoxygenation of boiler fuel was consumed 14.47 MPa molecular hydrogen to produce the pure hydrocarbon mixture. 
Table 2. Comparison of oxidized product, boiler fuel and hydrocarbon mixture physical and chemical properties.

\begin{tabular}{|c|c|c|c|}
\hline Properties & $\begin{array}{c}\text { Oxidized } \\
\text { product }\end{array}$ & Boiler fuel & $\begin{array}{c}\text { Hydrocarbon } \\
\text { mixture }\end{array}$ \\
\hline $\mathrm{HHV}, \mathrm{MJ} / \mathrm{kg}$ & 15.40 & 35.40 & 45.30 \\
\hline Oxygen, wt\% & 58.96 & 14.0 & 0 \\
\hline $\begin{array}{c}\text { Total acid value, } \\
\mathrm{mg} \mathrm{KOH} / \mathrm{g}\end{array}$ & 161.0 & 51.6 & 0 \\
\hline $\mathrm{pH}$ & 2.87 & 4.24 & 9.5 \\
\hline Water content, vol\% & 33.75 & 2.7 & 0.08 \\
\hline Density, g/ml & 1.14 & 1.04 & 0.88 \\
\hline $\begin{array}{c}\text { Kinematic viscosity, } \\
40^{\circ} \mathrm{C}, \mathrm{cSt}\end{array}$ & 6.63 & 28.25 & 2.38 \\
\hline
\end{tabular}

Wildschut et al. [19] performed two-stage HDO by which a hydrotreating $1^{\text {st }}$ stage was followed by a hydrocracking $2^{\text {nd }}$ stage on bio-oil with noble metal catalysts. $\mathrm{Ru} / \mathrm{Al}_{2} \mathrm{O}_{3}, \mathrm{Ru} / \mathrm{C}$, $\mathrm{Ru} / \mathrm{TiO}_{2}, \mathrm{Pd} / \mathrm{C}, \mathrm{Pt} / \mathrm{C}, \mathrm{CoMo} / \mathrm{Al} 2 \mathrm{O} 3$, and sulfide $\mathrm{NiMo} / \mathrm{Al}_{2} \mathrm{O}_{3}$ were tested. The hydrotreating $1^{\text {st }}$ stage was applied to bio-oil at a temperature of $250{ }^{\circ} \mathrm{C}$ and 100 bar hydrogen pressure and was followed by $2^{\text {nd }}$ stage hydrocracking at a temperature of $350{ }^{\circ} \mathrm{C}$ and 200 bar hydrogen pressure for $4 \mathrm{~h}$ in an autoclave reactor. The $1^{\text {st }}$ stage mildly deoxygenated hydrocarbon yields ranged between 21 to $58 \mathrm{wt} \%$ and the oxygen content ranged between 18.5 to $26.5 \mathrm{wt} \%$. $\mathrm{Pd} / \mathrm{C}$ was found to be the best choice for the $1^{\text {st }}$ stage hydrotreating process. The $2^{\text {nd }}$ stage hydrocracking process liquid hydrocarbon oil yields ranged between 25 to $65 \mathrm{wt} \%$ and oxygen content ranged between 6 and $11 \mathrm{wt} \%$.

Wildschut et al. [27] also reported an experimental study to gain insights into catalyst stability of ruthenium on alumina $\left(\mathrm{Ru} / \mathrm{Al}_{2} \mathrm{O}_{3}\right)$, ruthenium on carbon $(\mathrm{Ru} / \mathrm{C})$ and platinum on carbon $(\mathrm{Pt} / \mathrm{C})$ catalysts for the hydrotreatment of fast pyrolysis oil at $350{ }^{\circ} \mathrm{C}$ and 200 bar hydrogen pressure for 4 hours in a batch reactor set-up. Researchers concluded that ruthenium or platinum on carbon catalysts provided equally superior yield and deoxygenation. The highest oil yield obtained with $\mathrm{Ru} / \mathrm{C}$ was about $65 \mathrm{wt} \%$ with reduction of oxygen content from 40 to $6 \mathrm{wt} \%$. They also concluded that prolonged reaction time led to decreased end-product yields and increased levels of oxygen content. These results may be due to the gasification of the products and depolymerisation of solids. However, complete deoxygenation of bio-oil was not achieved in this process due to the mild conditions applied.

Elliot et al. [18] proposed a two-stage reactor configuration. A first reactor was operated below $280{ }^{\circ} \mathrm{C}$ using a pressure of typically 140 bar and a LHSV (liquid hourly space velocity, volume of oil per unit volume of catalyst per hour) of 0.62 to "stabilize" the oil by hydrotreating the most reactive compounds. A subsequent deep deoxygenation step was performed in a second reactor at higher temperatures, typically $350{ }^{\circ} \mathrm{C}$, under hydrogen at a total pressure of $142 \mathrm{bar}$ and an LHSV of 0.11 volume of oil (volume of catalyst) $1 \mathrm{~h}-1$. 
As mentioned above various researchers performed deoxygenation of bio-oil by consumption of high amount of molecular hydrogen between 100-200 bar. In this work our results indicated that we have reduced consumption of molecular hydrogen compared to previous researchers by utilization of syngas.

Fig. 1 Shows the elemental composition weight percentages of the oxidized product, boiler fuel and hydrocarbon mixture. The carbon content of the boiler fuel of $76.4 \mathrm{wt} \%$ increased from that of the oxidized product at $33.10 \mathrm{wt} \%$. Carbon content of the hydrocarbon mixture was 87.06. The oxygen content of the oxidized product decreased from $58.96 \mathrm{wt} \%$ to $14.0 \mathrm{wt} \%$ for boiler fuel to zero for the hydrocarbon mixture. Nitrogen content was not altered by CDO.

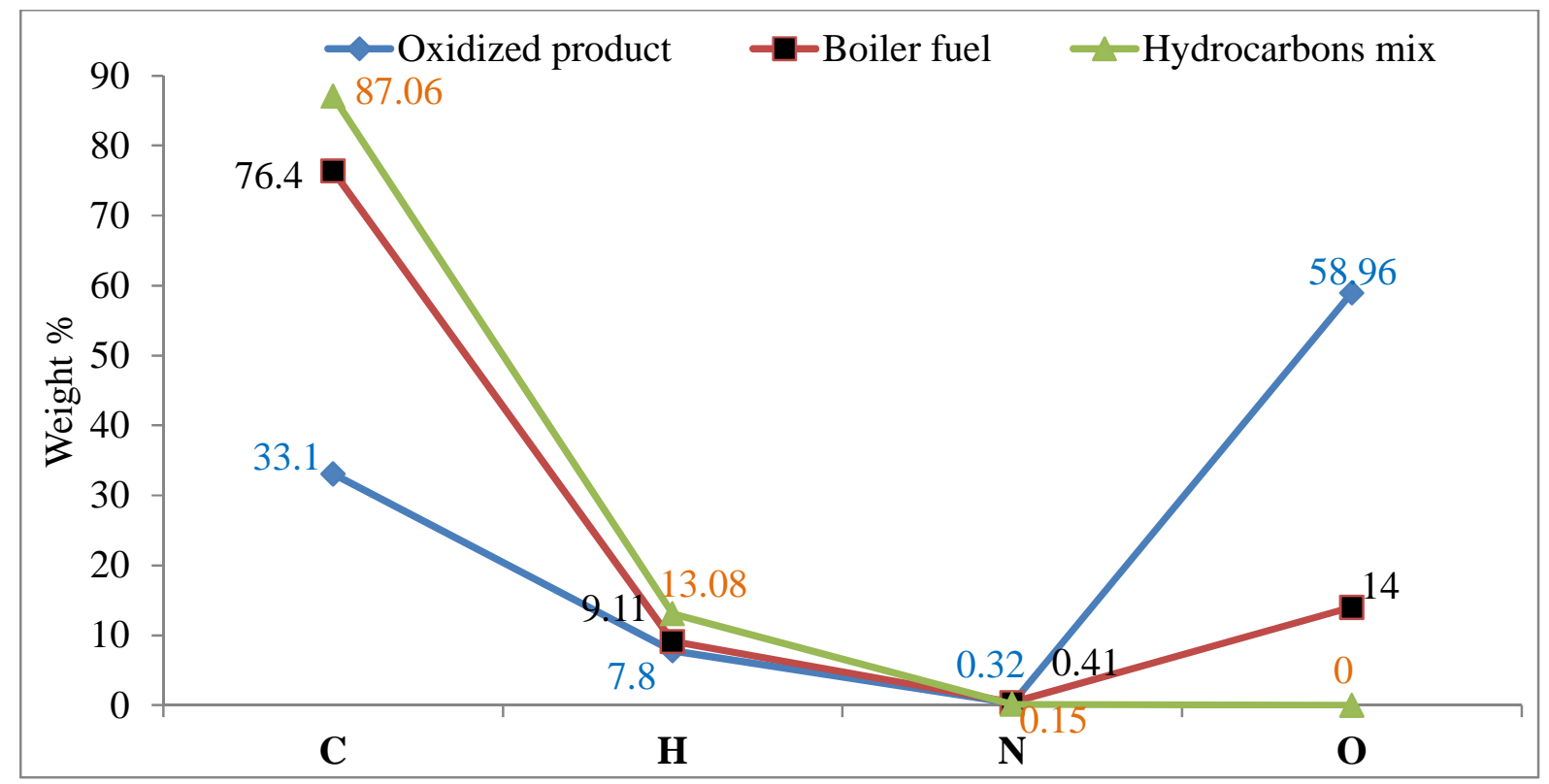

Fig. 1. Oxidized product, boiler fuel and hydrocarbon mixture elemental analysis comparison.

A DHA was performed by ASTM D6730-01. This test is often referred to the as PIANO method (paraffins, iso-paraffins, aromatics, naphthenes and olefins) to classify the hydrocarbons present in the hydrocarbon mixture. The results of the DHA are given in Figure 2. These results show that the hydrocarbon mixture contained n-paraffins of 6.84 mass $\%$, iso-paraffins of 17.51 mass $\%$, olefins of 26.90 mass $\%$, naphthenes of 13.78 mass $\%$, aromatics of 7.21 mass $\%$, total C14+ of 15.02 mss\% and unknown compounds of 10.04 mass\%. This DHA analysis also calculated the liquid hydrocarbon mixture octane number of 61.8 . 


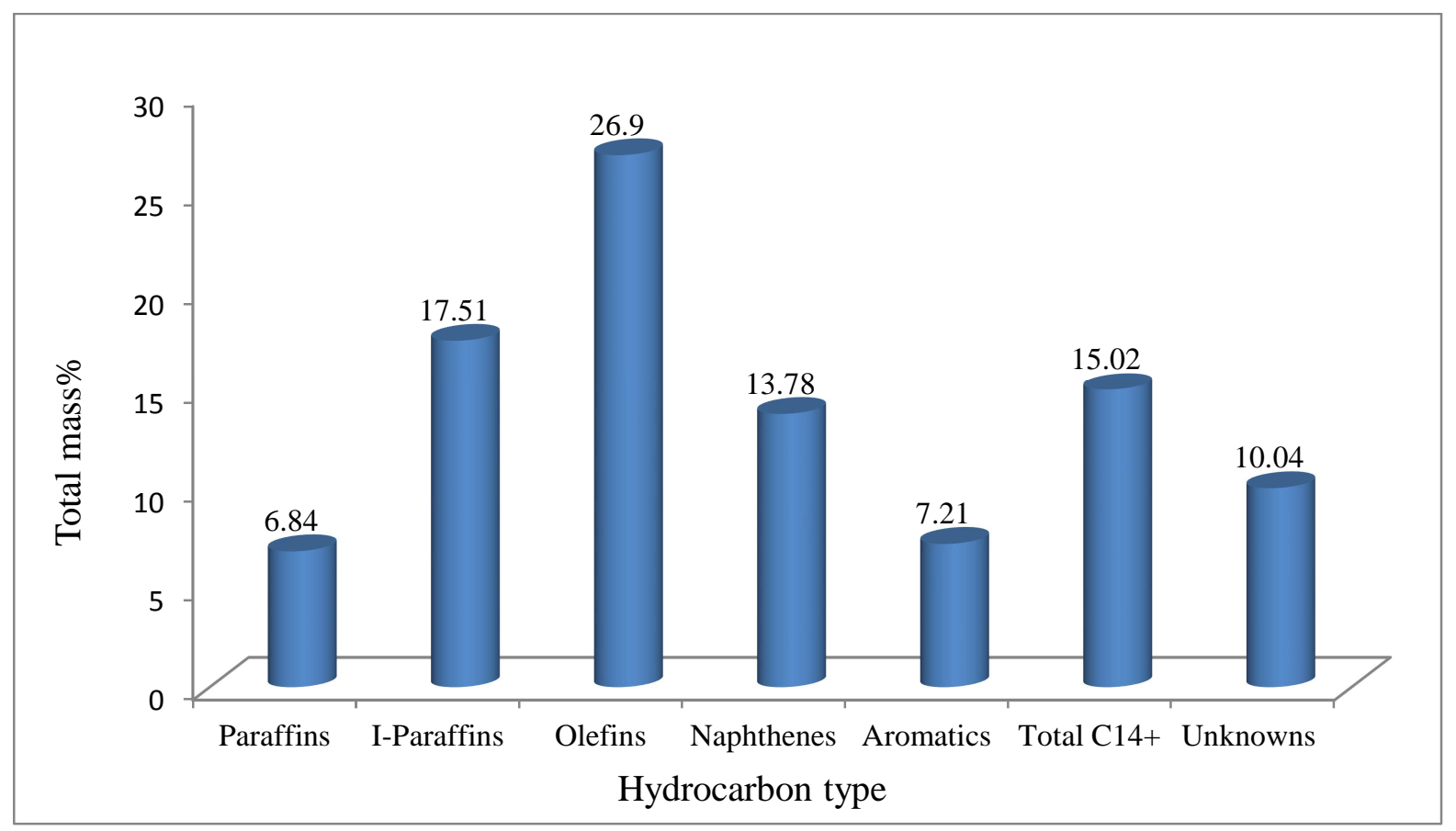

Fig. 2. Hydrocarbon types and their mass percentages present in liquid hydrocarbon mixture results analyzed by DHA ASTM D6730-01.

Simulated distillation of the hydrocarbon mixture was performed by ASTM D2887 for boiling range distribution of petroleum fractions by gas chromatography. Simulated distillation of the hydrocarbon mixture results are shown in Fig. 3 as the petroleum fuel equivalent based on vaporization temperature. These boiling temperatures are given below the named petroleum equivalents. These petroleum equivalents were of the molecular weights of gasoline $(45 \%)$, jet fuel $(20 \%)$ and diesel $(30 \%)$. Not shown in Fig. 3 is the $5 \%$ of heavy fuel produced at temperatures above $350{ }^{\circ} \mathrm{C}$. 


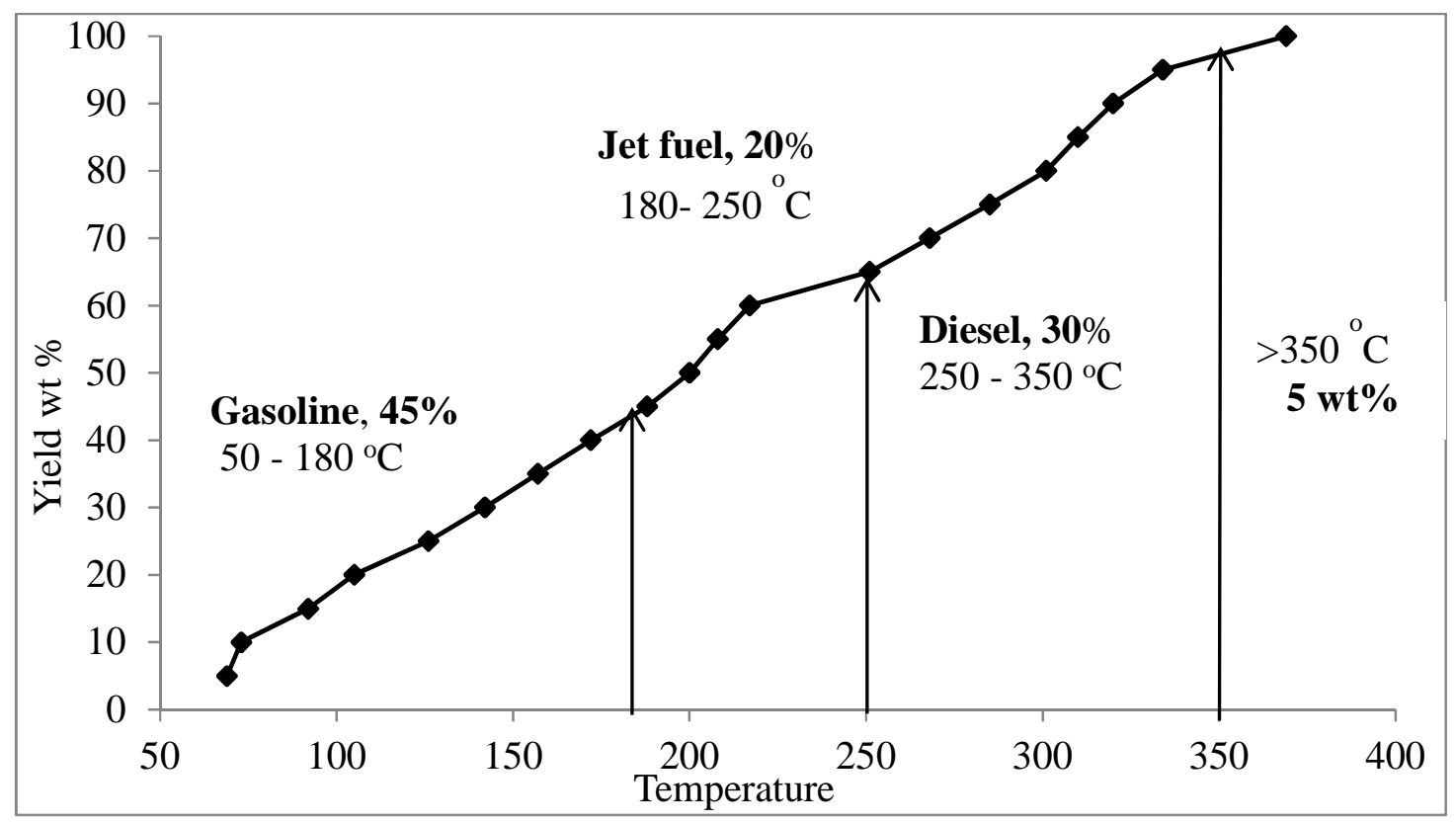

Fig. 3. Gasoline, jet fuel and diesel fuels weight percentages present in hydrocarbon mixture results from simulated distillation analysis by the ASTM D2887.

Fig. 4 shows the comparison of oxidized product, boiler fuel and hydrocarbon mixture FTIR spectra. These spectra identified the functional groups present in the product types. Characteristic vibrational modes were observed at $3200-3600 \mathrm{~cm}^{-1}$ (OH stretch), $2800-3100 \mathrm{~cm}^{-1}$ (CH aliphatic stretch), $1600-1750 \mathrm{~cm}^{-1}$ (C=O stretch), $1350-1470 \mathrm{~cm}^{-1}$ (CH bending) and 1000-1250 cm $\mathrm{cm}^{-1}(\mathrm{C}-\mathrm{O}$ stretch). The $\mathrm{OH}$ (carboxylic acids) stretching was decreased and $\mathrm{CH}$ (alkanes) aliphatic stretch and $\mathrm{CH}$ bending stretch absorption bands were significantly increased from oxidized product to boiler fuel and for the hydrocarbon mixture. The decrease in both $\mathrm{OH}$ and $\mathrm{C}=\mathrm{O}$ stretch absorption bands and increase in $\mathrm{CH}$ aliphatic stretch absorption band indicate that the carboxylic acids and other oxygenated chemical compounds were converted into hydrocarbons. The findings of the FTIR spectra are in good agreement with the physical and chemical properties described in Table 2 and DHA results in Fig. 2. 


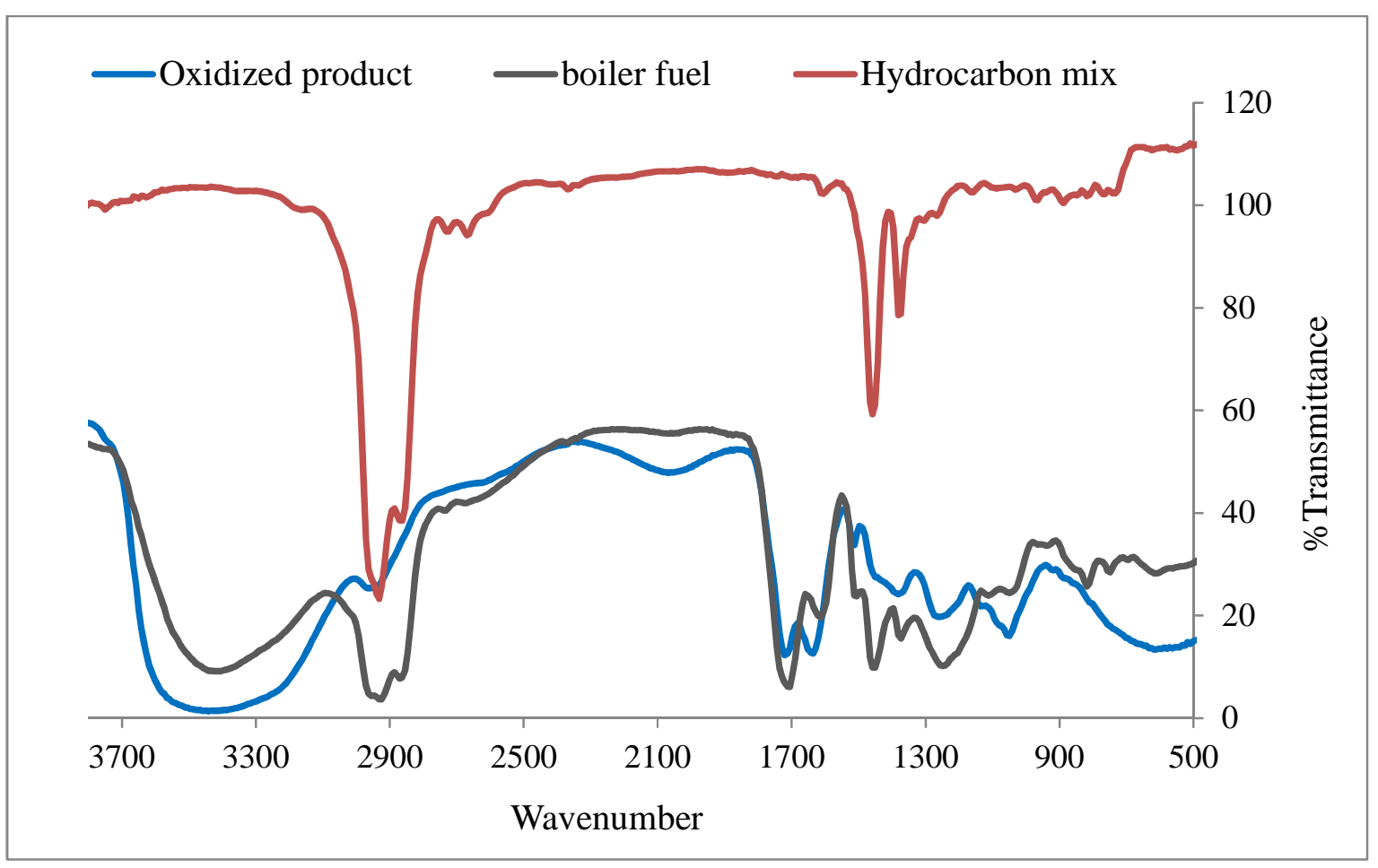

Fig. 4. FTIR spectra comparing oxidized product, boiler fuel and hydrocarbon mixture.

Proton NMR spectra of the oxidized product (a), syngas partial deoxygenated product (b), liquid hydrocarbon mixture (c) and commercial gasoline-jet fuel-diesel mixture (d) are shown in Fig. 5. As shown in Fig, 5 (a), (b) and (c) it is evident that there is a significant difference between ${ }^{1} \mathrm{H}-\mathrm{NMR}$ spectrum of the oxidized product, syngas partial deoxygenated product and hydrocarbon mixture. The oxidized product spectrum Fig. 5(a) is very complex and consists of a large number of proton signals due to the presence of various compounds with differing functional groups. After the catalytic deoxygenation of the oxidized product the number of proton signals reduced significantly in the partially deoxygenated product spectrum (Fig. 5(b)) and fully deoxygenated product spectrum (Fig. 5(c)). This was due to the conversion of various oxygenated compounds to aliphatic and aromatic hydrocarbons.

Comparison of Figs. 5(a) and 5(b) show clearly that the partial deoxygenation of oxidized product eliminated the methoxy $\left(-\mathrm{OCH}_{3}\right)$ group of guaiacol or substituted guaiacol compounds (one of the major components of the bio-oil). The methoxy group singlet proton signal with a downfield chemical shift of 5.2 ppm present in Fig. 5(a) was absent in Fig. 5(b).

Comparison of the Fig. 5(a) spectra of oxidized bio-oil to the partially deoxygenated spectra of Fig. 5(b) shows that the phenols, substituted phenols and other aromatic compounds' (derived from lignin and sugars) proton signals had a downfield chemical shift of 5.8-8.0 ppm. Likewise comparison of Fig. 5(a) and 5(b) show that some oxygenated compounds' proton signals demonstrated a chemical shift of 2.0-2.8 ppm (acyl, benzylic and aliphatic hydroxyl functional groups) during partial deoxygenation. Again, for the same comparison of Fig. 5(a) and 5(b) spectra partial deoxygenation caused other oxygenated compounds' proton signals to chemically shift from 3.2-5.2 ppm (esters, ethers, lignin derived methoxy phenols). Therefore, phenols, substituted phenols and the described two groups of oxygenated compounds were all reduced in 
1 the spectra of Fig. 5(b) as compared to the oxidized product (Fig. 5(a)) as a result of partial 2 deoxygenation. By contrast to the reduction of oxygenated compounds contrast, the aliphatic 3 hydrocarbons proton signals with an upfield chemical shift of 0.8-1.8 ppm were increased. A 4 similar increase was also observed in the aromatic hydrocarbons proton signals with a chemical 5 shift of 6.4-7.6 ppm in Fig. 5(b) as compared to Fig. 5(a) due to the conversion of phenols and 6 guaiacols to aromatic hydrocarbons during the partial deoxygenation.

7

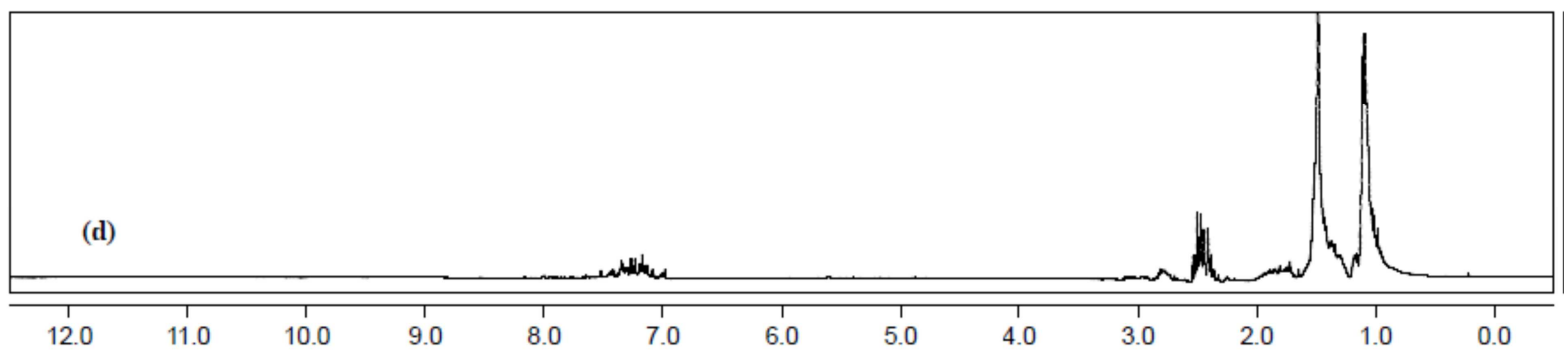

8 $\mathrm{ppm}(\mathrm{t} 1)$

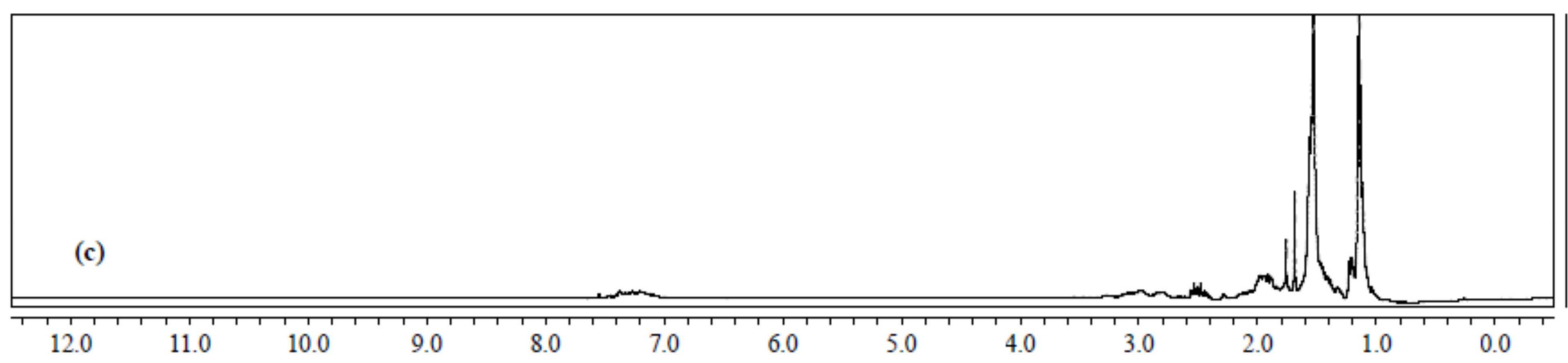

$\operatorname{ppm}(\mathrm{f1})$

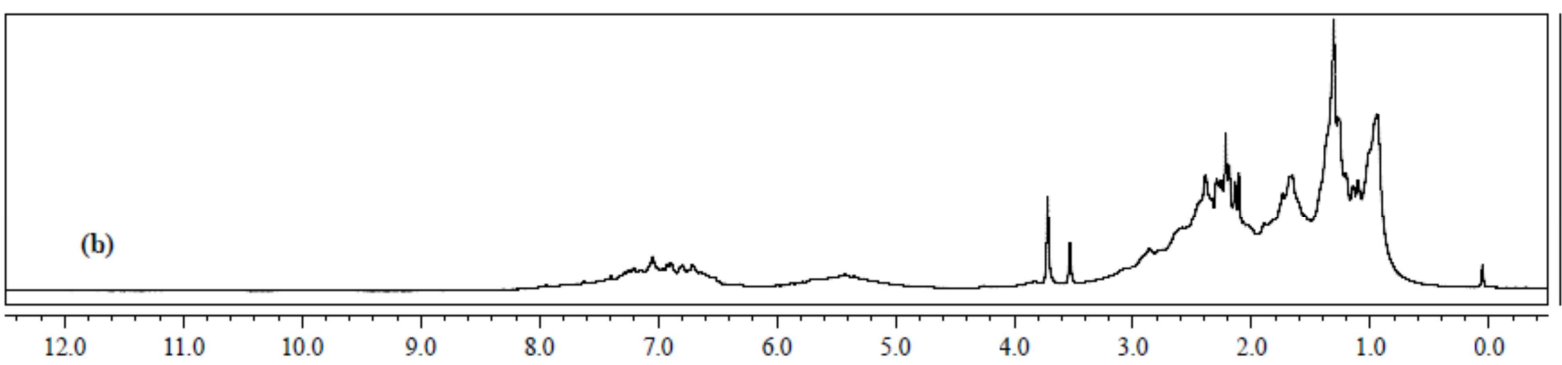

$\operatorname{ppm}(\mathrm{t} 1)$

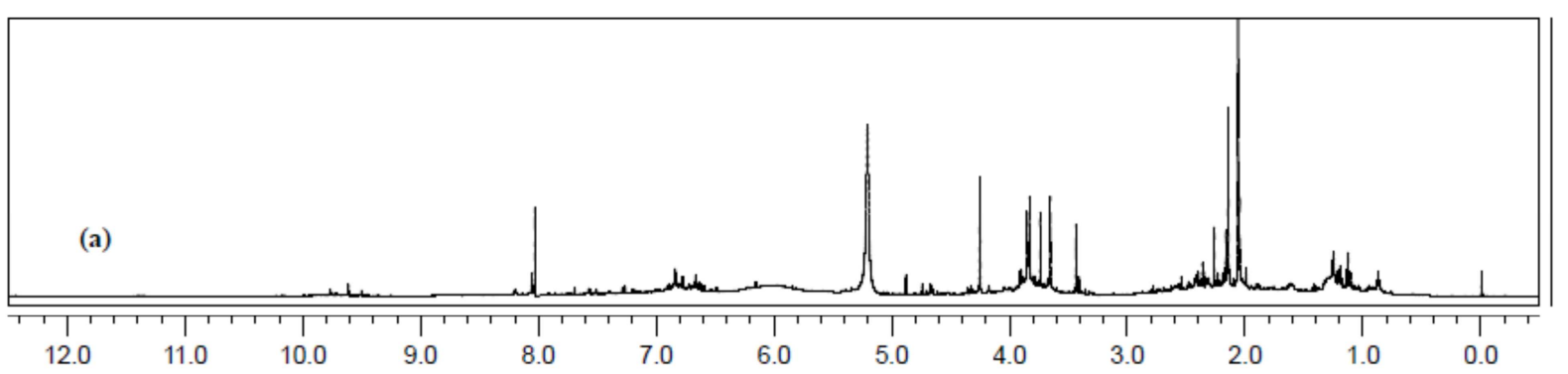
$\mathrm{ppm}(\mathrm{t} 1)$

Fig. 5. ${ }^{1} \mathrm{H}-\mathrm{NMR}$ spectra analysis of oxidized product (a), partial deoxygenated product (b), hydrocarbon mixture (c) and commercial gasoline-jet fuel-diesel mixture (d). 
As shown in Fig. 5(c) the full hydrogen deoxygenation step applied to the syngas partially deoxygenated product of Fig. 5(b) increased the aliphatic alkanes' (hydrocarbons) proton signals with an upfield chemical shift of 0.8-1.8 ppm. By contrast to the increase in aliphatic alkanes' upfield shift comparison of Fig. 5(b) to 5(c) shows that some remaining aromatic compounds, phenols and substituted phenols were reduced with a downfield chemical shift of 5.0-7.5 ppm. Likewise, the esters, ethers, carbonyl compounds and hydroxyl groups' proton signals demonstrated a downward chemical shift of 3.2-5.2 ppm. Therefore, the full deoxygenation spectra in Fig. 5(c) showed an increase in aliphatic alkane groups. However, there was considerable reduction in the phenols, substituted phenols, esters, ethers carbonyl compounds and hydroxyl groups in Fig. 5(c) spectra. Both the increase and decrease of proton signals discussed was due to the conversion of several oxygenated and aromatic compounds to aliphatic hydrocarbons during the full deoxygenation.

The liquid hydrocarbon mixture (comprised of gasoline, jet fuel and diesel weight compounds) produced by this study ${ }^{1}$ H-NMR spectrum Fig. 5(c) was also compared with the commercial gasoline-jet fuel-diesel mixture (prepared by physical mixing of equal parts of commercial gasoline, jet fuel and diesel) ${ }^{1}$ H-NMR spectrum Fig. 5(d). As shown in Fig. 5(c) and $5(d)$, it is very clear that both spectra proton signals each other resemble. The fact of this resemblance is further strengthened by the results of the DHA analysis (Fig. 2), simulated distillation analysis (Fig. 3) and FTIR spectra analysis (Fig. 4).

Table 3 shows the micro GC analysis of the input pressurized syngas applied for partial deoxygenation and exit gas compositions resulting from the partial deoxygenation reactions of both input syngas and hydrogen. As shown in Table 3, input syngas was comprised of $18.0 \%$ of $\mathrm{H}_{2}, 22.0 \%$ of $\mathrm{CO}$ and $11 \%$ of $\mathrm{CO}_{2}$; exit gas from the syngas partial deoxygenation reaction was comprised of $1.1 \%$ of $\mathrm{H}_{2}, 5 \%$ of $\mathrm{CO}$ and $38.8 \%$ of $\mathrm{CO}_{2}$. The exit gas produced from the syngas partial deoxygenation reaction indicates consumption of 17 percentage points of $\mathrm{CO}$; in addition, the reaction resulted in the production of an additional 28.8 percentage points of $\mathrm{CO}_{2}$. This high consumption of $\mathrm{CO}$ and the high production of $\mathrm{CO}_{2}$ during the syngas partial deoxygenation step indicate that the Scheme 2 WGS reaction occurred between the $\mathrm{CO}$ present in the syngas and $\mathrm{H}_{2} \mathrm{O}$ present in the bio-oil to produce hydrogen and $\mathrm{CO}_{2}$ as a byproduct.

As shown in Table 3, based on the exit gases calculations the partial deoxygenation using molecular hydrogen consumed 49 percentage points compared to the partial deoxygenation occurred with 17 percentage points of syngas-hydrogen. Comparing the $\mathrm{CO}_{2}$ exit gases of both partial deoxygenation reactions utilizing molecular hydrogen and syngas; the $\mathrm{CO}_{2}$ evolved for partial deoxygenation occurred utilizing syngas was $144 \%$ higher than partial deoxygenation occurred utilizing molecular hydrogen. The consumption of $\mathrm{CO}$ during the partial deoxygenation utilizing syngas was also in good agreement with the occurrence of the WGS as mentioned in the reaction scheme 2. Approximately 5.23 MPa of syngas-hydrogen (syngas comprised of $18 \%$ of hydrogen) was consumed per liter of bio-oil to perform partial deoxygenation of bio-oil using syngas. But, for partial deoxygenation utilizing pure hydrogen consumed was approximately 15.36 MPa of molecular hydrogen per liter of bio-oil. The hydrogen consumption in our syngas partial deoxygenation was reduced by approximately $66 \%$ compared to the molecular hydrogen partial deoxygenation. The partial deoxygenation was successfully occurred utilizing syngashydrogen comprised of $22 \%$ of $\mathrm{CO}$ by reacting with $33.75 \mathrm{wt} \%$ of $\mathrm{H}_{2} \mathrm{O}$ present in the oxidized bio-oil (1:1.53) in the presence of WGS catalyst. 
Table 3. Partial deoxygenation reaction In-gas and exit-gas components analysis by micro GC analyzer.

\begin{tabular}{|c|c|c|c|}
\hline Sample Name & $\mathbf{H}_{\mathbf{2}} \%$ & $\mathbf{C O} \%$ & $\mathbf{C O}_{\mathbf{2}} \%$ \\
\hline Syngas [In gas] & 18.0 & 22.0 & 11.0 \\
\hline $\begin{array}{c}\text { Syngas partial deoxygenation } \\
\text { [Exit gas] }\end{array}$ & 1.1 & 0.0 & 38.8 \\
\hline $\begin{array}{c}\text { Hydrogen [In gas] } \\
\text { Hydrogen partial deoxygenation } \\
\text { [Exit gas] }\end{array}$ & 100.0 & 0.0 & 0.0 \\
\hline
\end{tabular}

Pure hydrogen was also applied to perform the partial deoxygenation of the oxidized product as a comparative control of exit gas composition. This comparative test utilizing pure hydrogen was performed by applying the same $1^{\text {st }}$ stage partial deoxygenation reaction conditions as mentioned in section 2.2.2. As shown in Table 3 the exit gas from the hydrogen partial deoxygenation reaction was comprised of $51.0 \%$ of $\mathrm{H}_{2}, 0.6 \%$ of $\mathrm{CO}$ and $15.9 \%$ of $\mathrm{CO}_{2}$. This result indicated that $49 \%$ of the input $100 \%$ hydrogen was required (leaving $51 \%$ in the exit gas) to perform the partial deoxygenation under the conditions applied. The release of the small respective percentages of $0.6 \% \mathrm{CO}$ and $15.9 \% \mathrm{CO}_{2}$ would be expected during the pure hydrogen partial deoxygenation reaction.

A remaining question is whether the $\mathrm{H}_{2}$ contained in the input syngas combined with the $\mathrm{H}_{2}$ produced by the WGS reaction performed satisfactory deoxygenation of the oxidized bio-oil. Table 4 repeats the description of the syngas partial deoxygenated product given in Table 2 above to allow a comparison to the study results of pure hydrogen partial deoxygenated product performed on oxidized bio-oil. A comparison of these Table 4 results shows that there was very little difference between the partially deoxygenated product produced by pure hydrogen and syngas partial deoxygenation product. HHV, acid value, $\mathrm{pH}$, water content, density and viscosity have nearly equivalent values with the greatest difference in the oxygen content values. The oxygen value difference showed a lower oxygen content value $(14.0 \mathrm{wt} \%)$ for the syngas partial deoxygenation product compared to the pure hydrogen partial deoxygenated product $(15.1 \mathrm{wt} \%)$, a $7.2 \%$ decrease. Therefore, it can be concluded that the syngas partially deoxygenated and hydrogen partially deoxygenated products are nearly identical. This indicates that the $\mathrm{H}_{2}$ contained in the raw syngas combined with that added by the WGS reaction provided sufficient $\mathrm{H}_{2}$ to drive the partial deoxygenation reaction to the same degree as for pure hydrogen when performed on identical samples of oxidized bio-oil.

As reported by many practitioners Elliot et al. [18], Wildschut et al. [19], Wildschut et al. [27] and Parapati et al. [33] consumption of high amount of molecular hydrogen between 100200 bar to perform deoxygenation of bio-oil. In this work our results indicated that we have reduced consumption of molecular hydrogen compared to previous researchers. 
Table 4. Comparison of some physical and chemical properties of boiler fuels produced from both syngas and hydrogen partial deoxygenation reactions.

\begin{tabular}{|c|c|c|}
\hline Properties & $\begin{array}{c}\text { Boiler fuel } \\
\text { [Syngas] }\end{array}$ & $\begin{array}{c}\text { Boiler fuel } \\
\text { [Hydrogen] }\end{array}$ \\
\hline HHV, MJ/kg & 35.40 & 34.50 \\
\hline Oxygen, wt\% & 14.00 & 15.10 \\
\hline $\begin{array}{c}\text { Total acid value, } \\
\mathrm{mg} \mathrm{KOH/g}\end{array}$ & 51.60 & 48.60 \\
\hline $\mathrm{pH}$ & 4.24 & 4.20 \\
\hline Water content, vol\% & 2.70 & 2.70 \\
\hline Density, g/ml & 1.04 & 1.00 \\
\hline $\begin{array}{c}\text { Kinematic viscosity, } \\
40^{\circ} \mathrm{C}, \mathrm{cSt}\end{array}$ & 28.25 & 28.00 \\
\hline
\end{tabular}

\section{Conclusions}

The pretreatment of raw bio-oil followed by a partial deoxygenation in the presence of pressurized syngas and full deoxygenation with pure hydrogen successfully produced liquid hydrocarbons of transportation fuel quality. Upgrading with syngas appears to provide sufficient hydrogen required for CDO of oxidized bio-oil reactions. Simultaneously, the CDO large reduction in water content in the partially deoxygenated product that is produced by the WGS should render the final hydrogen deoxygenation step more efficient in hydrogen utilization. The liquid hydrocarbons produced from CDO had an HHV of $45.30 \mathrm{MJ} / \mathrm{kg}$. The oxygen content of raw bio-oil was decreased from $53.58 \mathrm{wt} \%$ to $0.0 \mathrm{wt} \%$ of the syngas CDO hydrocarbon mixture. Acid value and water content were nearly zero. $\mathrm{pH}$ was on the basic side at 9.5. Density and viscosity were considerably lowered at $0.88 \mathrm{~g} / \mathrm{ml}$ and $2.38 \mathrm{cSt}$, respectively. The energy density of hydrocarbons produced by this method was increased by approximately $182 \%$ from raw biooil. Our results indicated that the syngas partially deoxygenated and hydrogen partially deoxygenated products were nearly identical. DHA, ${ }^{1} \mathrm{H}-\mathrm{NMR}$, FTIR and simulated distillation analysis resulted that the liquid hydrocarbon mixture produced by this study (CDO) were comprised of petroleum equivalent molecular weights of gasoline $(45 \%)$, jet fuel $(20 \%)$ and diesel (30\%).

\section{Acknowledgement}

This research was performed based upon work funded through the Sustainable Energy Research Center at Mississippi State University (MSU) and is supported by the Department of Energy under Award Number DE-FG3606GO86025. We thank Dr. Fei Yu of Department of Agricultural and Biological Engineering, MSU, for supplying compressed syngas for our experiments. We also thank B. K. Mitchel of Department of Sustainable Bioproducts, MSU, for assistance in the production of bio-oil by fast pyrolysis. 


\section{Disclaimer}

This report was prepared as an account of work sponsored by an agency of the United States government. Neither the United States Government nor any agency thereof, nor any of their employees, makes any warranty, express or implied, or assumes any legal liability or responsibility for the accuracy, completeness, or usefulness of any information, apparatus, product, or process disclosed, or represents that its use would not infringe privately owned rights. Reference herein to any specific commercial product, process, or service by trade name, trademark, manufacturer, or otherwise does not necessarily constitute or imply its endorsement, recommendation, or favoring by the United States Government or any agency thereof. The views and opinions of authors expressed herein do not necessarily state or reflect those of the United States Government or any agency thereof.

\section{References}

[1]. Maggi, R., B. Delmon. Comparison between 'slow' and 'flash' pyrolysis oils from biomass. Fuel. 73, 5, 671-667, 1994.

[2]. Bridgwater, A.V., D. Meier, D. Radlein. An overview of fast pyrolysis of biomass. Organic. Geochemistry. 30, 1479-1493, 1999.

[3]. Mohan, D., C. U. Pittman, Jr., P. Steele. Pyrolysis of wood-biomass for bio-oil: A Critical Review. Energy \& Fuels. 20, 848-889, 2006.

[4]. Ingram, L., D. Mohan, M. Bricka, P. Steele, D. Strobel, D. Crocker, B. Mitchell, J. Mohammad, K. Cantrell, C. U. Pittman, Jr. Pyrolysis of wood and bark in an auger reactor: physical properties and chemical analysis of the produced bio-oils. Energy \& Fuels. 22, 614-625, 2008.

[5]. Mckendry, P. Energy production from biomass (Part 1): Overview of biomass. Bioresource. Technology. 1, 83, 37-46, 2002.

[6]. Huber, G. W., S. Iborra, A. Corma. Synthesis of transportation fuels from biomass: Chemistry, catalysts, and engineering. Chemical. Review. 106, 4044-4098, 2006.

[7]. Oasmaa, A., D. C. Elliott, J. Korhonen. Acidity of biomass fast pyrolysis bio-oils. Energy \& Fuels. 24, 6548-6554, 2010.

[8]. Hu, X., C. Li, Y. Xu, Q. Wang, X. Zhu. On the thermal oxidation stability of pyrolysis biomass oil. Int. J. of Renewable Energy Technology. 2, 2, 155-168, 2011.

[9]. Bandi, A., F. Baumgart, A. V. Bridgwater. Stirling engine with flox burner fuelled with fast pyrolysis liquid. In: Progress in Thermochemical Biomass Conversion. Blackwell Science: Oxford, 1459-1467, 2001.

[10]. Czernik, S., A. V. Bridgwater. Overview of applications of biomass fast pyrolysis oil. Energy \& Fuels. 18, 590-598, 2004.

[11]. Schnepf, R., B. D. Yacobucci. Renewable fuel standard (RFS): Overview and issues. CRS Report for Congress. March 14, page 4, 2013.

[12]. Solecki, M., A. Scodel, B. Epstein. Advanced biofuel market report. Environmental. Entrepreneurs. August 27, 2013.

[13]. Furimsky, E. Catalytic hydrodeoxygenation. Applied Catalysis A: 199, 147-190, 2000.

[14]. Elliott, D. C. Historical developments in hydroprocessing bio-oils. Energy \& Fuels. 21, 1792-1815, 2007. 
[15]. Corma, A., G. W. Huber, L. Sauvanaud, P. O. Connor. Processing biomass-derived oxygenates in the oil refinery: Catalytic cracking (FCC) reaction pathways and role of catalyst. Journal of Catalysis. 247, 307-327, 2007.

[16]. Tan, E. C.D., T. L. Marker, M. J. Roberts. Direct production of gasoline and diesel fuels from biomss via integrated hydropyrolysis and hydroconversion process - A technoeconomic analysis. Environmental Progress \& Sustainable Energy. May 31, 2013. DOI: 10.1002/ep.11791.

[17]. Czernik, S., R. Evans, R. French. Hydrogen from biomass-production by steam reforming of biomass pyrolysis oil. Catalysis Today. 129, 3-4, 2007.

[18]. Elliott, D. C., T. R. Hart, G. G. Neuenschwander, L. Rotness, M. V. Olarte, A. H. Zacher, Y. Solantausta. Catalytic hydroprocessing of fast pyrolysis bio-oil from pine sawdust. Energy \& Fuels. 26, 3891-3896, 2012.

[19]. Wildschut, J., F. H. Mahfud, R. H. Venderbosch, H. J. Heeres. Hydrotreatment of fast pyrolysis oil using heterogeneous noble-metal catalysts. Industrial \& Engineering Chemistry Research. 48, 10324-10334, 2009.

[20]. Ardiyanti, A.R., A. Gutierrez, M. L. Honkela, A. O. I. Krause, H. J. Heeres. Hydrotreatment of wood-based pyrolysis oil using zirconia-supported mono and bimetallic (Pt, Pd, Rh) catalysts. Applied Catalysis A: General. 407, 56-66, 2011.

[21]. Gagnon, J., S. Kaliaguine. Catalytic hydrotreatment of vacuum pyrolysis oil from wood. Industrial \& Engineering Chemistry Research. 27, 1783-1788, 1988.

[22]. Subramaniam, B., W. F. Jackson, C. V. Raghunath. Deoxygenation of bio-oils and other compounds to hydrocarbons in supercritical media. Patent Pub. No. US2011/0028773 A1, 2011.

[23]. Dickerson, T., J. Soria. Catalytic fast pyrolysis: A Review Energies. 6, 514-538, 2013.

[24]. Wang, H., J. Male, Y. Wang. Recent advances in hydrotreating of pyrolysis bio-oil and its oxygen-containing model compounds. ACS Catal. 3, 1047-1070, 2013.

[25]. Jones, S. B., J. E. Holladay, D. C. Elliot, C. Valkenburg, D. J. Stevens, C. W. Walton, C. Kinchin, S. Czernik. Production of gasoline and diesel from biomass via fast pyrolysis, hydrotreating and hydrocracking: A design case. Pacific Northwest National Laboratory. $18284,2009$.

[26]. Elliott, D. C., E. G. Baker. Process for upgrading biomass pyrolyzates. US Patent 4,795,841, 1989.

[27]. Wildschut, J., C. I. Melian, H. J. Heeres. Catalyst studies on the hydrotreatment of fast pyrolysis oil. Applied Catalysis B: Environmental. 99, 1-2, 298-306, 2010.

[28]. Bulushev, D. A., J. R. H. Ross. Catalysis for conversion of biomass to fuels via pyrolysis and gasification: A review. Catalysis Today. 171, 1, 1-13, 2011.

[29]. Diebold, J. P. A review of the chemical and physical mechanisms of the storage stability of the fast pyrolysis bio-oils. NREL/SR-570-27613. January, 2000.

[30]. Hu, X., D. M. Wang, R. Gunawan, C. Lievens, W. Chaiwat, M. Gholizadeh, L. Wu, X. Li, C. Z. Li. Polymerization on heating up of bio-oil: A model compound study. AICHE Journal. 59, 3, 888-900, 2013.

[31]. Xu, J., J. Jiang, W. Dai, T. Zhang, Y. Xu. Bio-oil upgrading by means of ozone oxidation and esterification to remove water and to improve fuel characteristics. Energy \& Fuels. 25, 1798-1801. 2011.

[32]. Steele, P. H., S. K. Tanneru, S. K. Gajjela. Composition and methods for improved fuel production. US Patent 2013/0291431 A1, 2013. 
[33]. Parapati, D. R., V. K. Guda, V. K. Penmetsa, P. H. Steele, S. K. Tanneru. Single stage hydroprocessing of pyrolysis oil in a continuous packed bed reactor. Environmental Progress \& Sustainable Energy. February 13, 2014, DOI: 10.1002/ep.11954.

[34]. Tanneru, S. K., P. H. Steele. Pretreating bio-oil to increase yield and reduce char during Hydrodeoxygenation. Fuel. 133, 326-331, 2014.

[35]. Street, J., F. Yu, J. Wooten, E. Columbus, M. G. White, J. Warnock. Gasoline-range hydrocarbon production using biomass derived synthesis gas over Mo/ $\mathrm{H}^{+} \mathrm{ZSM}-5$. Fuel. 96, 239-249, 2012.

[36]. Smith, B. R. J., M. Loganathan, M. S. Shantha. A review of the water gas shift reaction kinetics. Int. J. of Chemical Reactor Engineering. Review R4, 8, 2010.

[37]. Nagai, M., M. A. Zahidul, Y. Kunisaki, Y. Aoki. Water-gas shift reactions on potassiumand zirconium-promoted cobalt molybdenum carbide catalysts. Applied Catalysis A: General. 383, 58-65, 2010.

[38]. Akgul, G., A. Kruse. Influence of salts on the subcritical water-gas shift reaction. The J. of Supercritical Fluids. 66, 207-214, 2012.

[39]. Yan, Q., F. Yu, Z. Cai, J. Zhang. Catalytic upgrading nitrogen-riched wood syngas to liquid hydrocarbon mixture over a Fe-Pd/ZSM-5 catalyst. Biomass and Bioenergy. 47, 469-473, 2012.

[40]. Idakiev, V., D. Mihajilova, B. Kunev, A. Andreev. Effect of copper oxide on the catalytic acticity of iron-chromia catalyst for water gas shift reaction. Reaction Kinetics and Catalysis Letters. 33, 1, 119-124, 1987.

[41]. Nkafamiya, I. I., H. M. Maina, S. A. Osemeahon, U. U. Modibbo. Percentage oil yield and physiochemical properties of different groundnut species (Arachis hypogaea). African J. of Food Science. 4, 7, 418-421, 2010. 